\title{
Antarctic moisture flux and net accumulation from global atmospheric analyses
}

\author{
W. F. Budd, P. A. Reid AND L.J. Minty \\ Antarctic Cooperative Research Centre, University of Tasmania, GPO Box 252C, Hobart. Tasmania 7001, Australia
}

\begin{abstract}
Previous attempts to derive the Antarctic surface net accumulation distribution from atmospheric-moisture fluxes, in reasonable agreement with the observed distribution, have encountered many difficulties. The present analysis uses the Australian Bureau of Meteorology Global Atmospheric Assimilation and Prediction Scheme (GASP), which has been operational since 1989, to derive the net air-mass and moisture fluxes over the Antarctic. It is shown that the annual mean net surface accumulation closely resembles the glaciologically observed distribution and provides a physical basis for the observed pattern, through the moisture transports. The variations with latitude and elevation and through the annual cycle are also well reproduced. Although some mass-closure errors still exist, they are expected to become insignificant with the new generation of improved analysis schemes. Consequently the atmospheric analyses can provide a sound basis for both assessing the performance of global climate models in simulating Antarctic accumulation rates and monitoring long-term changes which may occur with global warming.
\end{abstract}

\section{INTRODUCTION}

Changes in the Antarctic ice-sheet mass balance are of considerable concern in regard to possible sea-level changes as a consequence of global warming (Houghton and others, 1990). The Antarctic ice-sheet net accumulation and the total mass losses are each about $2000 \mathrm{~km}^{3} \mathrm{a}^{-1}$, equivalent to about $6 \mathrm{mma}^{1}$ of sea-level change Budd and Smith, 1985). Consequently a significant change in the major components of the Antarctic mass balance could influence the current rate of sea-level rise of about $1.5 \mathrm{mma}^{-1}$ (Houghton and others, 1990). Components of the mass balance include precipitation, evaporation, condensation, surface melt, basal melting and iceberg calving. Since the floating-ice component does not influence sea-level change, the flow or transfer of ice from grounded to floating is important, and net change in grounded ice mass above floating is the quantity that needs to be monitored.

The most important consequences for the mass balance to be expected from future warming are increased basal melting under the floating ice, increased precipitation and increased evaporation. Estimates of possible increases in precipitation and evaporation, which are very much dependent on the sea-ice cover, have been made by Budd and Simmonds (1991) from experiments with general-circulation models GCMs). Timing of the likely onset of the warming can best be estimated at present from the most recent long transient simulations of global warming with increasing greenhouse gases (Manabe and Stouffer 1993; Cubasch and others, 1994).

The reaction of the Antarctic ice sheet to projected increases in basal melt rate and surface net accumulation has been studied by Budd and others (1995). Their results indicated that increases in net accumulation over the grounded ice would contribute directly towards a sealevel decrease. Increased basal melting was found to cause loss mainly from the floating ice; although there was greatly increased flow from the grounded ice, much of it was from below the floating level. The net consequence was that during the next $100-500$ a period the net loss from basal melting (for rates up to $10 \mathrm{ma}^{-1}$ ) and increased ice flow could be offset by the expected increases in net accumulation, which were taken to be in the range of 50 $100 \%$ over that time span.

In the time-frame of the next few hundred years, therefore, it is apparent that the most important component of the Antarctic ice-sheet mass balance for sea-level change is the net surface accumulation which may offset some of the rise expected from ocean thermal expansion and increased melting of non-polar glaciers. The purpose of this paper is to increase our understanding of the physical basis of the observed net accumulation by examining how well the spatial distribution and annual cycle can be reproduced from analyses of moisture transport based on atmospheric observations. This will also allow us to monitor future changes and their causes and will help with evaluating GCM simulations of the present climate and future projections.

\section{PREVIOUS ANALYSES OF NET ATMOSPHERIC MOISTURE TRANSPORT OVER ANTARCTICA}

The concept of using atmospheric moisture transport to derive net accumulation over Antarctica goes back a long way (Meinardus 1938; Loewe 1957). However, it was not 
until a reasonable number of meteorological stations was established during the International Geophysical Year (1957/58) that it became possible to compute a detailed flux budget. Rubin (1960, 1962) examined mass, heat and moisture fluxes and budgets of the Antarctic from the atmospheric transport across the boundaries based on radiosonde data. Rubin's (1962) derived budget was found to be in reasonable agreement with his compilation of net accumulation. The approach used by Rubin suffers from a number of problems, including the large spacing between stations; lack of adequate data at the higher levels and the lower boundary layer; and the use of monthly mean data for winds and moisture to compute fluxes.

Similar large-scale moisture-flux budgets have been computed by Howarth (1983) and Howarth and Rayner (1986), but these analyses also are too coarse to derive detailed net accumulation distributions over Antarctica. Bromwich $(1988,1990)$ used detailed radiosonde data to compute net moisture transports across the Antarctic coastline and the implied net mass budgets. The locations of the stations were still not comprehensive enough to give complete coverage over the continent, particularly for West Antarctica. Connolley and King (1993) and Connelley and others (1993) also carried out an extensive analysis using radiosonde data to compute moisture fluxes including annual and inter-annual variations. Again the data are too sparse to compute mass budgets over the entire continent. Masuda (1990) used the ECMWF (European Centre for Medium-Range Weather Forecasts) analyses of the detailed FGGE-year data (1978-79) to compute the Antarctic net accumulation poleward of $70^{\circ} \mathrm{S}$ and made a similar study for the Arctic. A detailed diagnostic study of moisture flux and precipitation for Greenland using meteorological analyses was carried out by Bromwich and others (1993). The most comprehensive analysis for the Antarctic so far has been by Yamazaki (1992), who used the U.S. National Meteorological Center's (NMC) twice-daily analyses for the 5 year period 1986-90 to compute moisture-flux convergence over the Antarctic. The horizontal resolution was $2.5^{\circ} \times 2.5^{\circ}$ with relative humidity at six standard levels from 1000 to $300 \mathrm{hPa}$. The spatial variations of moisture and moisture flux were examined through the annual cycle and inter-annually. An Antarctic net accumulation map was derived, but the low interior values were obscured by uncertainty. The total net annual accumulation and annual cycle were shown to agree quite well with observations. A similar study was carried out by Reid (1993), using the Australian Bureau of Meteorology's Southern Hemisphere archive, 1978-88, and he obtained similar general results to those of Yamazaki. In 1989 the Australian Bureau of Meteorology upgraded its analyses to a global spectral model with wave number (rhomboidal) R31, nine vertical levels and improved physics, as described by Bourke and others (1991). The Bureau of Meteorology Research Centre (BMRC) spectral model, with $\sigma$-levels following the surface topography, has been found to be particularly effective for the Antarctic, and the improved physics makes these analyses more suitable than the previous Southern Hemisphere analyses (on a $47 \times 47$ grid) for examining mass and moisture fluxes over the Antarctic. Since 1993 the analysis system has been upgraded to wave number R53 and 19 levels in the vertical, with further improved performance. Here, for the sake of consistency, we use just the 3 years of GASP R31 L9 data, from 1989 to 1992.

\section{GHARACTERISTICS OF THE ATMOSPHERIC ASSIMILATION-AND-PREDICTION SCHEME}

The basic principle of the assimilation scheme is to use the numerical model to incorporate all the global observational data into the model in a physically balanced way, at regular time intervals, and, by running the model forward in time, to provide the first guess for the data at the next time interval. The techniques used for the BMRC assimilation-and-prediction scheme are described by Hart and others (1993). The observational data include surface observations from the meteorological stations, automatic weather stations and drifting buoys, and vertical profiles from radiosonde stations and satellite soundings (TOVS). The scheme employs intermittent (six-hourly) forward assimilation, univariate analysis and adiabatic non-linear normal-mode initialization. The data insertion is considered in the sequence: surface pressure, temperature, moisture and winds. The physics of the analysis-and-prediction model is similar to that of the BMRC climate model which has been described in detail by Hart and others (1990). A few of the salient features are worth mentioning here.

The spectral model uses the terrain-following $\sigma$ vertical-relative-pressure coordinate scheme whereby the pressure at the surface is the lowest level and subsequent levels are at fixed fractions of the surface pressure. These fractions are: $0.991,0.925,0.811,0.663,0.500,0.336$, $0.188,0.074$ and 0.008 . The spectral representation is transformed to a Gaussian grid where the latitudinal spacing between points is approximately $2.3^{\circ}$ latitude, and approximately $2^{\circ}$ longitude at $60^{\circ} \mathrm{S}$, which converges with the meridians of longitude to the poles. Compared with the radiosonde data the model analyses are quite comprehensive in coverage. Twice-daily analyses have been used for the present study. In the time-frame of $0.5 \mathrm{~d}$ the atmospheric motion is controlled primarily by the advection of vorticity. This means that with the present data the model, over time, does a reasonable job of filling the gaps in the data coverage to the resolution of the grid points.

\section{TECHNIQUE USED FOR MOISTURE TRANSPORT AND FLUX}

The model analyses include moisture and winds at all levels for all grid points. From these the moisturetransport fluxes and divergences of flux can be computed. The net flux divergence in the columns gives the net accumulation $(A)$ or the difference in precipitation $(P)$ and evaporation $(E)$, i.e. $(P-E)$, over the surface of the topography. At this stage we do not consider driftsnow transport. Integral closures can be carried out to check total mass and moisture over an area with the net fluxes across the boundaries. The data have been used to examine the monthly means and annual cycles of total air 


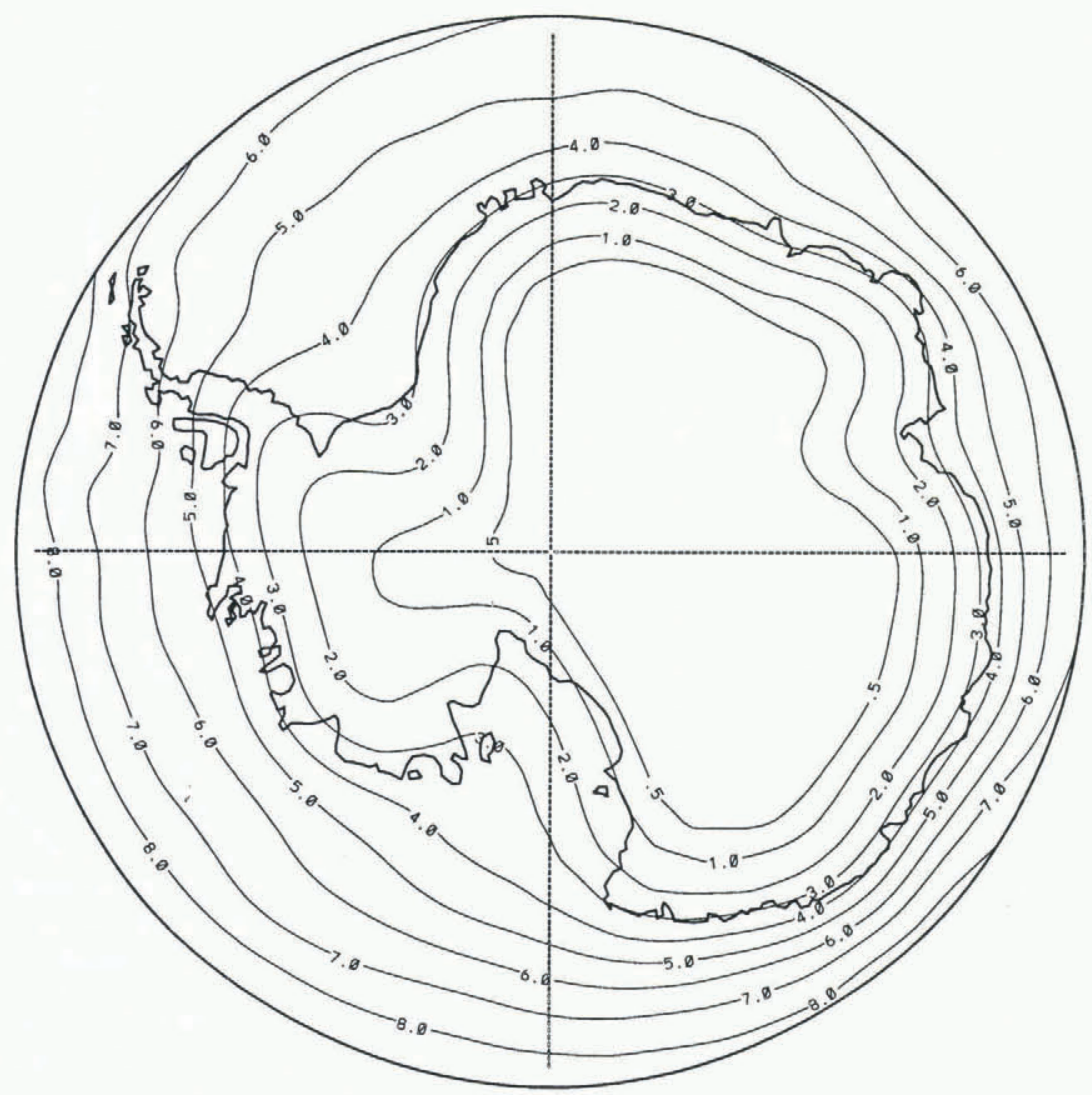

Fig. 1. The annual mean total column moisture over the Antarctic region (in mm of water) shows a strong decrease with increasing surface elevation. Above $2.5 \mathrm{~km}$ there is generally less than $0.1 \mathrm{~mm}$ total water.

mass, total column moisture and total mass and moisture fluxes over the Antarctic continent and as functions of elevation and latitude.

\section{RESULTS OF NET MOISTURE-CONVERGENCE ANALYSIS}

The total vertical-column moisture is strongly controlled by temperature and the water-vapour saturation relation. Equatorward of the Antarctic continent, over the ocean there is a strong gradient with latitude. Over the Antarctic continent the elevation is the dominant factor as shown by the annual average column moisture given in Figure 1. There is also a very strong annual cycle, with monthly mean values in summer being some $3-4$ times the corresponding winter values, as shown in Table 1. The net accumulation, however, is actually greater in winter than in summer. This is because it also depends on other factors such as temperature gradients, transport by winds and frequency of cyclonic activity, all of which show greater intensity in winter.

The total column moisture is very small compared to annual net accumulation. In fact the net fluxes inwards and outwards around the boundary of the Antarctic are large in comparison with the total column-moisture content and are equivalent to turning over the column moisture in the order of days, depending on the season. The inflow and outflow as a function of height, for summer, winter and annual mean, are shown along with the net transport in Figure 2.

Precipitation, evaporation, condensation and sublimation vary continually as the air moves around through the temperature gradients. The net accumulation is the difference between the total inflow and outflow fluxes, which are both large terms, compared to the net. In the

Table 1. Annual cycle of average column moisture and accumulation rate over Antarctica, from atmospheric analyses (w.e.)

\begin{tabular}{|c|c|c|c|c|c|c|c|c|c|c|c|c|c|}
\hline & Jan & $\mathrm{Feb}$ & Mar & $A p r$ & May & Jun & July & Aug & Sept & $\mathrm{Oct}$ & Nov & $D e c$ & Annual \\
\hline $\begin{array}{l}\text { Mean column } \\
\text { moisture }(\mathrm{mm})\end{array}$ & 3.7 & 3.2 & 2.3 & 1.8 & 1.4 & 1.1 & 1.0 & 0.8 & 1.0 & 1.4 & 2.1 & 3.4 & 1.93 \\
\hline \multicolumn{14}{|l|}{$\begin{array}{l}\text { Net accumulation } \\
\text { rate }\left(\mathrm{mm} \mathrm{a}^{-1}\right)\end{array}$} \\
\hline Overall & 101 & 150 & 174 & 188 & 180 & 172 & 174 & 162 & 186 & 151 & 143 & 108 & 157 \\
\hline Above $1500 \mathrm{~m}$ & 44 & 69 & 61 & 70 & 58 & 46 & 40 & 33 & 57 & 51 & 61 & 61 & 54 \\
\hline
\end{tabular}



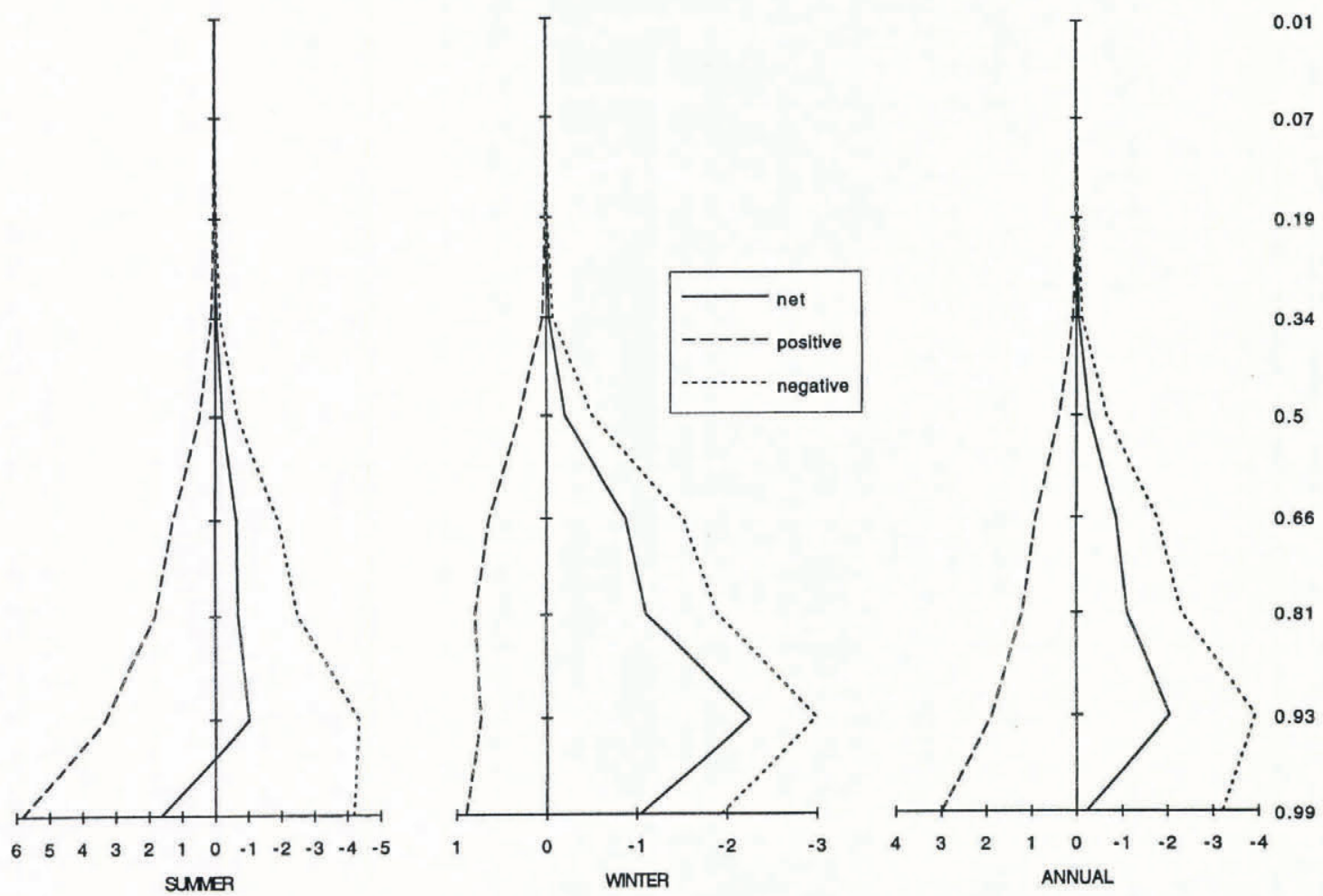

Fig. 2. Vertical profiles of moisture flux inwards (negative), outwards (positive) and net flux integrated around the Antartic coast $\left(a t 70^{\circ} S\right)$ as a function of elevation, given by the sigma pressure levels, for summer, winter and annual mean conditions. Units are $\mathrm{g} \mathrm{ms}^{-1}$.

annual total the inflow is greatest at about the $1000 \mathrm{~m}$ elevation range. In summer at low elevations near the coast, there is a net loss from the surface associated with greater net outflow, primarily associated with the katabatic winds and higher temperatures at lower elevations.

\subsection{Net accumulation distribution}

The pattern of net accumulation over the continent, as derived from the net fluxes, is shown in Figure 3, along with a compilation based on surface glaciological observations, from Giovinetto and Bull (1987).

The patterns are rather similar and show a marked distortion of the simple elevation pattern depicted by the mean column moisture. This distortion is strongly associated with the pattern of the winds which depends on the surface elevation of the topography as well as the pressure gradients. Figure $4 \mathrm{a}$ shows the pattern of surface winds superimposed on the spectral-model surface topography of the continent. Outside the Antarctic the mean wind flow depicts the main cyclonic regions around the continent. Over the continent the surface topography and katabatic winds also have a strong influence on the mean surface flow. The magnitudes of the accumulation rates from the glaciological observations, digitized to a $20 \mathrm{~km}$ grid, by Budd and Smith (1985), are compared with those from the GASP analyses, as a function of latitude and elevation, in Table 2.

Figure 4b shows the annual mean wind field, at the $0.811 \sigma$-level, superimposed on the accumulation distribution. It can be seen that the main coastal high-accumulation areas tend to be associated with regions of strong inflow. Similarly the lower-accumulation areas tend to be associated with mean wind outflow. This becomes more apparent when examining the winds at different levels, with inflow more related to the circulation of the lower troposphere and outflow more related to the near-surface katabatic flow. Although this applies in the mean, the highly dynamic nature of the circulation, with low-pressure centres moving continually around the coast, results in highly variable net inflow and outflow at all levels and locations.

\subsection{Annual cycle of net accumulation}

The variation in net accumulation through the annual cycle is very important because it provides a means of checking the ability of models to reproduce observations over a wide range of temperature, dynamics and

Table 2. Annual mean accumulation with latitudinal and elevation distribution from atmospheric analyses (GASP) and glaciological observations (Obs)

\begin{tabular}{lcccc}
\hline Latitude band & \multicolumn{2}{c}{ Elevation } & \multicolumn{2}{c}{ Accumulation rate } \\
& $\begin{array}{c}\text { Obs } \\
\mathrm{km}\end{array}$ & $\begin{array}{c}\text { GASP } \\
\mathrm{km}\end{array}$ & $\begin{array}{c}\text { Obs } \\
\mathrm{mm} \mathrm{a}^{-1}\end{array}$ & $\begin{array}{c}\text { GASP } \\
\mathrm{mm} \mathrm{a}^{-1}\end{array}$ \\
\hline $90-85^{\circ} \mathrm{S}$ & 2.76 & 2.53 & 68 & 61 \\
$85-80^{\circ} \mathrm{S}$ & 1.95 & 2.18 & 82 & 88 \\
$80-75^{\circ} \mathrm{S}$ & 1.94 & 2.05 & 135 & 145 \\
$75-70^{\circ} \mathrm{S}$ & 1.22 & 1.54 & 209 & 213 \\
Continent & & & 160 & 157 \\
\hline
\end{tabular}


(a)
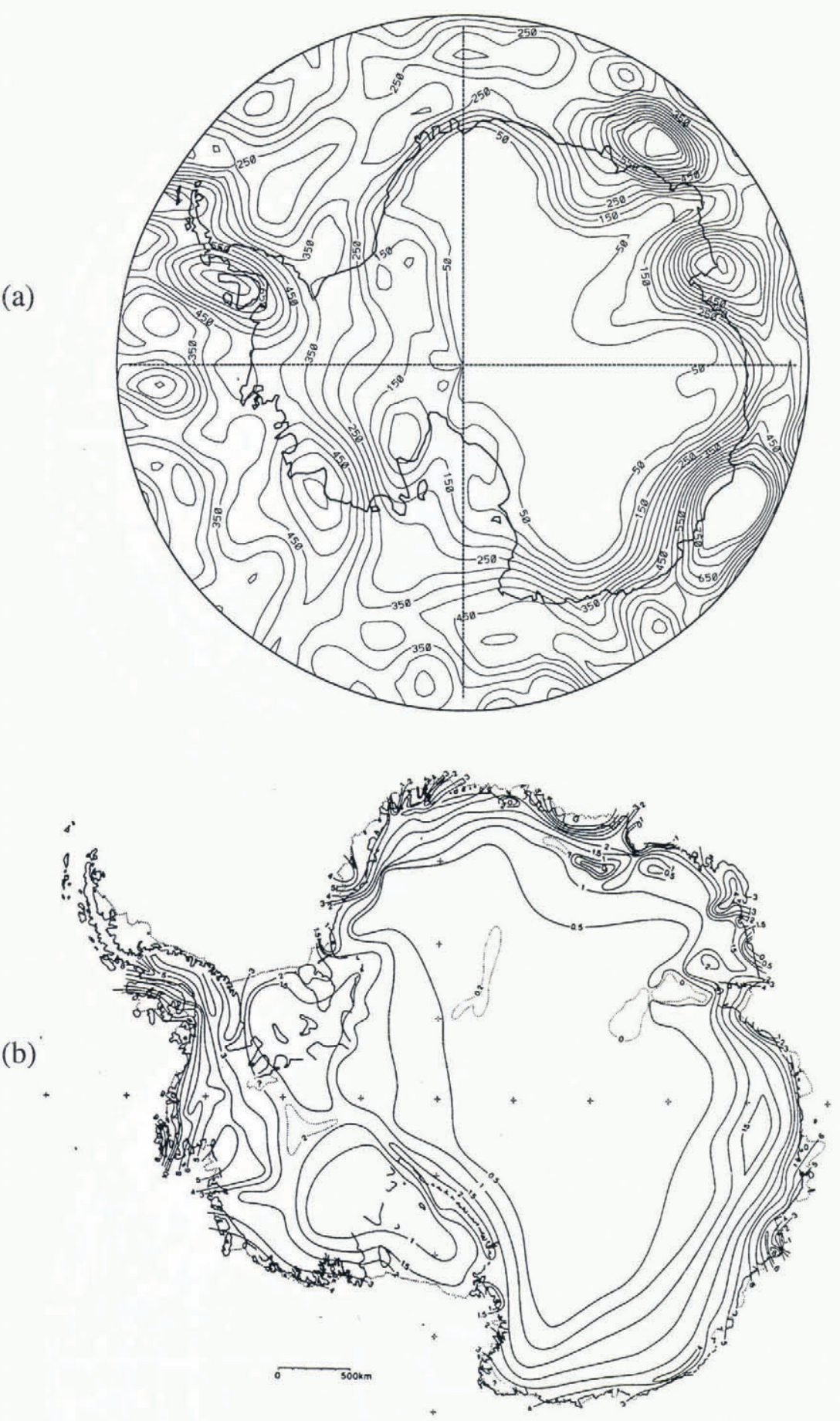

Fig. 3. a. The annual mean net surface accumulation from the moisture fluxes (in mmw.e. $a^{-1}$ ) as derived from the atmospheric GASP analyses. The pattern and magnitude of the distribution show strong similarity to the distribution compiled from glaciological observations by Giovinetto and Bull (1987) as shown in b.

circulation, etc. The results for the annual cycle from the moisture convergence of the analyses are shown in Figure 5 for different elevation regions. The total accumulation is dominated by the coastal region below $1500 \mathrm{~m}$, where there is a strong winter peak. For inland regions there is relatively little systematic variation during the year. A similar result was obtained from the U.S. NMC analyses by Yamazaki (1992). There is also relatively high variability from year to year, and frequently the highest accumulation occurs around the equinoxes.

Direct observational data for the annual cycle of net accumulation from glaciological measurements are still rather poor. The data available provide general support for the above results. Rusin (1961) provides a summary of IGY observations which indicate higher winter accumulation near the coast and relatively uniform accumulation, or more in summer, inland. Black and Budd (1964) show that a strong annual cycle of accumulation occurs in the coastal region of Wilkes Land, with winter build-up and summer deflation. Further inland the amplitude of the annual cycle decreased to give a relatively uniform accumulation rate. An important consequence of these results is that the total net accumulation varies during the year in an opposite way to the total column moisture. This implies that views relating net accumulation changes directly to 

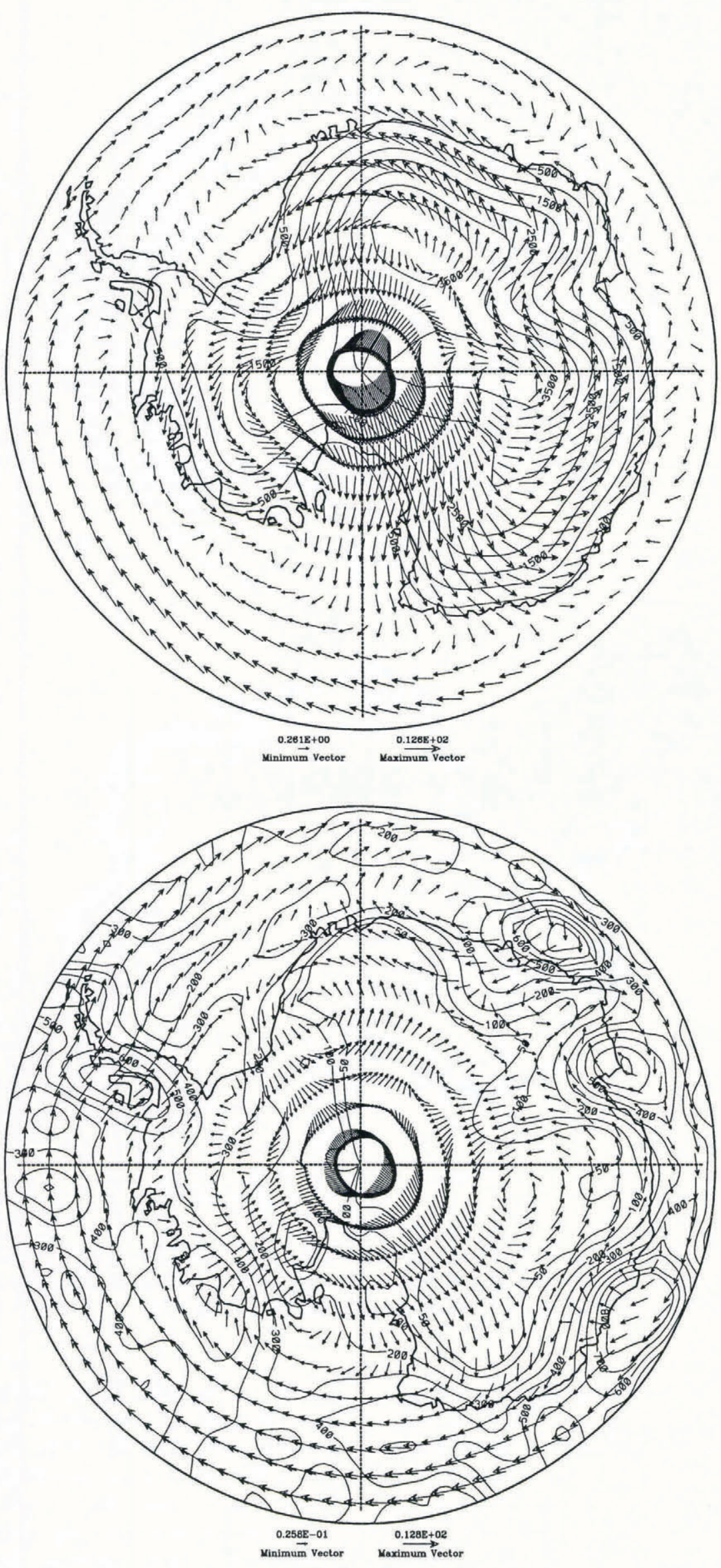

Fig. 4. a. The annual mean surface winds $\left(\mathrm{m} \mathrm{s}^{-1}\right)$ from the GASP analyses, superimposed on the R31 spectral topography. The pattern shows the strong influence of the topography and katabatic flow as well as the mean-pressure field. $b$. The annual mean net accumulation from GASP together with the mean surface wind field $\left(\mathrm{m} \mathrm{s}^{-1}\right.$ at sigma $=0.811$. The highand low-accumulation regions are clearly associated with inflow and oulflow, respectively, as well as with topography. 


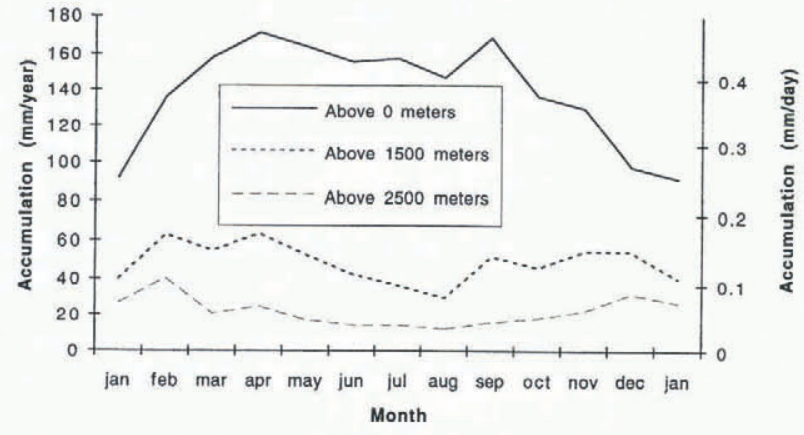

Fig. 5. The annual variation in net accumulation rate, as derived from the moisture convergence in the GASP analyses, shown for the whole of Antarctica and for the regions above 1500 and $2500 \mathrm{~m}$. In contrast to the column moisture the coastal accumulation rate tends to be larger in winter than in summer.

time changes of temperature are simplistic without adequate consideration also of changes in the dynamics. Similar limitations apply to the more comprehensive diagnostic relations derived for accumulation, such as those given by Giovinetto and others (1990).

\section{PROBLEMS STILL REMAINING}

Even though reasonable agreement has been found on the pattern of the areal distribution of accumulation and its variation through the year from the moisture-flux divergence and the glaciological observations, there are still a number of problems with the analyses. First, there are still significant closure errors for both mass and moisture. Erroneous negative-moisture amounts are generated, particularly at high elevations and over the interior. Higher resolution is still required: in the vertical, to provide better closure and improve the simulation of the lower boundary layer; and in the horizontal, to improve the treatment of flow around the topography. Similar problems were found by Trenberth (1991) for the lack of mass closure in the ECMWF analyses. He recommended the use of more frequent analyses (e.g. $4 \mathrm{~d}^{-1}$ ) to improve the closure. For the analysis presented here, the mass-closure error suggests an uncertainty in the net moisture flux and accumulation of $\pm 10 \%$.

So far, snow drift and surface melt have not been treated. This is not considered serious at this stage, since they affect only a small fraction of the coastal grid boxes and are not resolved. However, both could be computed diagnostically in a complete treatment. Finally there are still large gaps in the meteorological data coverage. This problem could be dealt with by increased numbers of drifting buoys, automatic weather stations and more sophisticated use of the satellite (TOVS) data over the continent.

\section{FUTURE DEVELOPMENTS}

The major global weather-analysis centres around the world have been improving their analyses by increasing their resolution, upgrading the physical parameteriza- tions and integrating more extensive observations into their analysis, such as cloud drift winds at upper levels, and scatterometer surface winds over the ocean. The Australian Bureau of Meteorology has introduced a new higher-resolution analyses scheme (R53, L19) with improved assimilation techniques, and their operational evaluations over 1 year indicate substantially improved performance. The use of higher-resolution nested grids over the Antarctic also promises improved performance for the moisture budget, and moisture-transport schemes involving a semi-Langrangian treatment also appear greatly to reduce the closure problems. The SCAR Antarctic meteorology program FROST (First Regional Study of the Troposphere) during 1994/95 should provide a valuable opportunity to evaluate more thoroughly the performance of the current analyses. Even now it is possible to monitor Antarctic moisture flux and accumulation on a continual basis, from daily time-scales to inter-annual variations, to compare with direct surface observations. It may then be possible to detect early signs of long-term trends above the background of the secular-type fluctuations described by Enomoto (1991).

\section{CONGLUSIONS}

Improvements in global meteorological analyses in recent years have made it possible to derive reasonable patterns of net accumulation over the Antarctic from the flux convergence of the moisture transport. The total net accumulation and its variation during the year is found to be in reasonable agreement with the data derived from glaciological observations. There is still a need to obtain a more comprehensive modern-accumulation data set from glaciological observations including the seasonal cycle. There are still problems with the meteorological analyses including low resolution, gaps in the observation coverage, and closure on the mass and moisture budgets.

Continuing improvements in analyses promise to provide a sound basis for assessing the performance of present-climate models and monitoring climatic change. In this way greater confidence can be generated for model simulations of future changes, of the Antarctic ice-sheet surface mass balance and of the implications for sea-level change.

\section{ACKNOWLEDGEMENTS}

The authors were greatly assisted by the Bureau of Meteorology in the provision of the GASP analyses and details of the model and analysis scheme. Also thanks are due to members of the Earth Sciences School of the University of Melbourne, particularly I. Simmonds and D. Jones for assistance with the preparation of the GASP data.

\section{REFERENCES}

Black, H. P. and W. Budd. 1964. Accumulation in the region of Wilkes. Wilkes Land, Antarctica. J. Glaciol., 5 (37), 3-15.

Bourke, W. and 7 others. 1991. Operational global assimilation and prediction in 
the Australian Bureau of Meteorology. Melbourne, Bureau of Meteorology Research Centre (Research Report 27), 54-72.

Bromwich, D. H. 1988. Snowfall in high southern latitudes. Rev. Geophys., 26 1), 149-168.

Bromwich, D. H. 1990. Estimates of Antarctic precipitation. Nature, $3436259), 627-629$.

Bromwich, D. H., F, M. Robasky, R. A. Keen and J. F. Bolzan. 1993. Modeled variations of precipitation over the Greenland ice sheet. $f$ Climate. 6 7), 1253-1268.

Budd, W. F. and 1. Simmonds. 1991. The impact of global warming on the Antarctic mass balance and global sea level. In Weller, G. E. L. L. Wilson and B. A. B. Severin, eds. International Conference on the Role of the Polar Regions in Global Change. Proceedings of a conference held June 11-15, 1990 at the University of Alaska Fairbanks. Vol. 2. Fairbanks, AK, University of Alaska. Geophysical Institute, 489494.

Budd, W.F. and I. N. Smith. 1985. The state of balance of the Antarctic ice sheet: an updated assessment 1984. In Glaciers, Ice Sheets, and Sea Level: Effect of a COO2 Induced Climatic Change. Report of a Workshop held in Seallle. Washington, September 13-15, 1984. Washington, DC, National Academy Press, 172177.

Budd, W. F. D. Jenssen. E. Mavrakis and B. Coutts. 1995. Modelling the Antarctic ice sheet changes through time. Ann. Glaciol., 20, 291-297.

Connolley, W. M. and J.C. King. 1993. Atmospheric water-vapour transport to Antarctica inferred from radiosonde data. Q. j. $R$. Meteorol. Soc., 119, 325-342.

Connolley, W. M., J. C. King and H. Cattle. 1993. Diagnostic studies of atmospheric water vapour transport to Antarctica, using radiosonde and GCM data. In Fourth International Conference on Southern Hemisphere Meteorology and Oceanography, March 29-April 2. 1993. Hobart, Australia. Boston, MA, American Meteorological Society, $446-447$.

Cubasch, U. and 7 others. 1994. A climate change simulation starting at an early time of industrialisation. Hamburg, Max-Plank-Institut für Meteorologie. Report 124.

Enomoto, H. 1991. Fluctuations of snow accumulation in the Antarctic and sea level pressure in the Southern Hemisphere in the last 100 years. Climatic Change, 18 1), 6787.

Giovinetto, M. B. and C. Bull. 1987. Summary and analysis of surface mass balance compilations for Antarctica, 1960-1985. Byrd Polar Research Centre. Report 1.

Giovinetto, M. B., N. M. Waters and C. R. Bentley. 1990. Dependence of Antarctic surface mass balance on temperature, elevation, and distance to open ocean. 7. Geophys. Res.. 95 D4), 3517-3531.

Hart, T. L., W. Bourke, B.J. McAvaney, B. W. Forgan and J. L.
McGregor. 1990. Atmospheric general circulation simulations with the BMRC global spectral model: the impact of revised physical parameterisations. F. Climate, 3, 436-459.

Hart, T. L., W. Bourke, P.J. Steinle and R. S. Seaman. 1993. Impact of higher resolution satellite soundings of temperature and moisture on large-scale numerical weather prediction. Mon. Wealher Rev., 121. $1746-1758$.

Houghton, J. T., G.J. Jenkins and J.J. Ephraums, eds. 1990. Climate change. The IPCC scientific assessment. Cambridge, Cambridge University Press.

Howarth, D. A. 1983. Seasonal variations in the vertically integrated water vapour transport fields over the Southern Hemisphere. Mon. Weather Rezi., 111, 1259-1272.

Howarth, D. A. and J. N. Rayner. 1986. Estimates of sources and sinks of atmospheric moisture in the Southern Hemisphere. In Second International Conference on Southern Hemisphere Meteorology, December I5, 1986, Wellington, New Zealand. Boston, MA, American Meteorological Society, 163-166.

Loewe, F. 1957. Precipitation and evaporation in the Antarctic. In Rooy, M. P. van, ed. Meteorology of the Antarctic. Department of Transport. Weather Bureau, 71-89.

Manabe, S. and R. J. Stouffer. 1993. Century-scale effects of increased atmospheric $\mathrm{CO}_{2}$ on the ocean-atmosphere system. Nature. $3646434), 215218$.

Masuda, K. 1990. Atmospheric heat and water budgets of polar regions: analysis of FGGE data. Proceedings of the NIPR Symposium on Polar Meleorology and Glaciology 3, 7988.

Meinardus, W. 1938. Klimakunde der Antarktis. Verlag Gebrüder Borntraegen.

Reid, P. A. 1993. An analysis of atmospheric mass and moisture fluxes over Antarctic. Graduate Diploma Thesis, University of Tasmania, Hobart.)

Rubin, M.J. 1960. Advection across the Antarctic boundary. In Anlarctic Meteorology; proceedings of the Symposium held in Melbourne, February 1959. New York, etc. Pergamon Press, 378-393.

Rubin, M.J. 1962. Atmospheric advection and the Antarctic mass and heat budget. Geophys. Monogr., Am. Geophys. Union 7, 149-159.

Rusin, N.P. 1961. Meleorological and radiational regime of Antarctica. Jerusalem, Israel Program for Scientific Translations.

Trenberth, K.E. 1991. Climate diagnostics from global analyses: conservation of mass in ECMWF analyses. J. Climate, 4, 707-722.

Yamazaki, K. 1992. Moisture budget in the Antarctic atmosphere. Proceedings of the NIPR Symposium on Polar Meteorology and Glaciology 6 , 36-45. 